\title{
Utilizing Educational Materials as a Mean for Improving Psychosexual Health of Breast Cancer Women
}

\author{
Sana Abasher \\ King Faisal University, Hofuf, KSA \\ Email: shajali@kfu.edu.sa
}

Received 13 June 2014; revised 20 July 2014; accepted 23 August 2014

Copyright (C) 2014 by author and OALib.

This work is licensed under the Creative Commons Attribution International License (CC BY). http://creativecommons.org/licenses/by/4.0/

\section{Abstract}

The psychological factors for Breast Cancer BrCa are very important, as they assist in improving the adaptation of the new situations they have to deal with. This study is to provide psycho-educational materials as intervention tools in enhancing coping with the psychosexual problems faced by Sudanese BrCa women. Study sample of 89 BrCa women were randomly selected to either educational group $(n=30)$, intervention group $(n=29)$, or control group $(n=30)$. To be eligible for the study, women were married, sexually active with their husbands, and inhabitant in Khartoum state during the implementation of the study. Two scales were been filled by all the participants as measurements for this study and those are: Watts Sexual Function Questionnaire (WSFQ) which measures and provides a total sexual function score and subscale score for desire, arousal, orgasm and satisfaction. Hospital Anxiety and Depression Scale (HADS) is the other measurement that used in this study. Significant difference has been found in regard to HADS and WSFQ pre- and post-test analysis for the experiential group. Women assigned to the educational materials group had significant higher posttest scores on both HADS and WSFQ scales than women assigned to psychosexual intervention program.

\section{Keywords}

Educational Materials, Breast Cancer, Sudanese Women, Psychosexual Health, Psychological Intervention

Subject Areas: Demography, Psychology

\section{Introduction}

Psychological intervention is one of the most important methods to help the patients with long lasting diseases, on top of which is cancer. Health education intervention varies in the amount of psychosocial information or 
coping instruction and behavioral training they provide. Their emphasis is generally on educating patients about their disease and its treatment. The education can also consist of coping strategies and communication skills [1].

Information is typically perceived as important, even by those who adopt a passive role in relation to treatment decision-making [2]. Written information is a preferred source of information among patients. It is popular because it provides a reference patients can return to when the need arises. It is also perceived by patients as a way to remove some of the burden of delivering information to family and friends. Written material can also improve patient's knowledge and help them prepare for complicated and potential life threatening procedures [2] [3]. Interviews with Japanese breast cancer survivors revealed that informants stated a strong psychological resistance to consulting healthcare professionals, male surgeons in particular, about sexual issues and wished to have a booklet about sexual and partnership issues [4].

The International Consensus Conference on Psychosocial Interventions in Cancer Patients provided basic guidelines and specific recommendations with regard to indications for psychosocial interventions in cancer patients. It was suggested that psychosocial interventions should be offered to patients with adjustment problems that lead to high levels of psychosocial distress as well to patients who themselves request psychotherapy [5]. Psycho-education as one of the forms of the psychosocial intervention, may be most effective during the diagnosis/pre-treatment time period, when patient information needs are high [6]. It provides information to individuals and groups about illness in a social, supportive interaction [7].

Several recent reviews and meta-analyses of psychosocial interventions in cancer have concluded that psycho-educational interventions are generally effective in enhancing coping with cancer, reducing emotional distress, and improving quality of life [8]. Offering an educational booklet in the form of a self-management booklet provides patients with the opportunity to read and learn at home, and to talk about it with family and friends. Written information has found to be the preferred type of information at post-treatment. In addition, it has the overwhelming benefit that serves as a permanent record to refresh patients' memory about what is already told by their clinician at a moment when they were too anxious to concentrate on the information. Finally, written information is easy to provide and allows patients' to read at their own pace and to review the topics when desired [9].

Therefore this presents study hypothizes that:

- The educational materials are effective in enhancing sexual health of breast cancer women.

- There are significant statistical differences in sexual health (post test) between the two experimental groups in favor of educational materials intervention.

- There are significant statistical differences in sexual health (post test) between educational group and control group in favor of educational group.

\section{Methodology}

Participants: Study sample were $89 \mathrm{BrCa}$ women who are being diagnosed with the disease and who were randomly selected. Participants in the study were selected to either; educational group $(n=30)$, intervention group $(n=29)$, or control group $(n=30)$. To be eligible for the present study, female married participants, living and sexually active with their husbands, diagnosed with $\mathrm{BrCa}$ and living in Khartoum state during the implementation of the study.

Instruments: Two scales were been filled by all the participants as measurements for this study and those are: Watts Sexual Function Questionnaire (WSFQ) This measure provides a total sexual function score and subscale score for desire, arousal, orgasm and satisfaction. Hospital Anxiety and Depression Scale (HADS) is the other measurement that used in this study. This scale consists of 14 items divided into two subscales termed anxiety and depression (score range, 0 to 21). Finally questions about the sample socio-demographic characteristics were also added.

The whole intervention program composed of: first; the educational material (for the educational group) and the second intervention is the 7 session's intervention program (for the intervention groups). The educational materials that contain booklet and varieties of handouts were given as reading materials to our target educational group and was acted as a memory aid that help them to increase their knowledge, enlighten them about the disease, sexual issues and information about nutrition.

\section{Result}

The first hypothesis stated that "The educational materials are effective in improving sexual health of $\mathrm{BrCa}$ 
women".

Table 1 explains the effectiveness role of the educational materials in enhancing the sexual and psychological state of women with breast cancer.

The 2nd hypothesis stated that "There are significant statistical differences in sexual health (post test) between the two experimental groups in favor of educational materials group".

To study this hypothesis the researcher used the $\mathrm{T}$ test for the independent two groups, results were explained in Table 2.

Table 2 shows that there were significant differences between the intervention program and the educational materials group in favor of the latter.

The 3rd hypothesis stated that "There are significant statistical differences in sexual health (post test) between educational materials group and control group in favor of educational materials group".

To study this hypothesis the researcher used the T test for the independent two groups. Results were as Table 3 shows.

Table 3 shows that there were no significant differences found between the educational materials and the control groups in regard to their sexual function. On the other hand, significant difference was found between the same groups regarding their psychological status.

\section{Discussion}

Significant difference has been found in regard to HADS and WSFQ pre and post test analysis for the experiential group (Table 1) which represent the group that have only the educational materials. The use of information booklets and leaflets could potentially relieve patients from some of their anxiety and help them feel more informed [10] [3] The use of a booklet, for example, with a broad spectrum of information is easy to implement, has the potential to reach a large number of patients, and might be more cost effective than individual or group tailored psychotherapeutic interventions. Beside it keeps the privacy of the couple when having written materials that enable them to share together in a relaxed state or condition.

Moreover, offering an educational booklet in the form of a self-management booklet provides patients the opportunity to read and learn at home, and to talk about it with family and friends as one of our patient recalled that she and her husband have no communication except for this educational materials as the husband started to read it for her because she is illiterate. Written information has found to be the preferred type of information at post-treatment, it has the overwhelming benefit that it serves as a permanent record to refresh patients' memory about what is already told by their clinician at a moment when they were too anxious to concentrate on the information. As many patients continue to have problems and need to be preparing for handling them, and because patients cease to visit the hospital regularly until their first follow-up, it is in general difficult for health-care providers to detect these problems and to intervene. In addition, patients may not always find their way to the health-care team during this post-treatment phase, hence, written information is easy to provide and allows patients' to read at their own pace and to review the topics when desired [9] especially that our respondents most of them are house wives, in their middle age and relatively educated regardless of not being highly educated (Table 4).

People with cancer express a strong desire for information to prepare themselves for treatment, particularly in relation to self-care. Two factors combine to underscore the important of providing patients with improved information about chemotherapy and providing skills to self-manage potential side effects. Firstly, it is known that many patients do not recall much of the information given within a medical consultation, in which initial information about chemotherapy is frequently provided. Secondly, chemotherapy treatment is most commonly given

Table 1. Explain $\mathrm{T}$ test for the one group to know the progress that happened to the BrCa women after introducing the Educational materials $(\mathrm{N}=30)$.

\begin{tabular}{|c|c|c|c|c|c|c|c|}
\hline Variables & Variable & No. & Mean & $\begin{array}{c}\text { Standard } \\
\text { Deviation }\end{array}$ & T. Value & $\begin{array}{c}\text { P. } \\
\text { Value }\end{array}$ & Conclusion \\
\hline HADS & $\begin{array}{l}\text { Before edu. materials } \\
\text { After edu. materials }\end{array}$ & 30 & $\begin{array}{l}9.23 \\
5.89\end{array}$ & $\begin{array}{c}4.79 \\
2.849\end{array}$ & 4.071 & 0.000 & $\begin{array}{l}\text { Sig. Statistical decrease } \\
\text { in Anxiety \& Depression }\end{array}$ \\
\hline WSFQ & $\begin{array}{l}\text { Before edu. materials } \\
\text { After edu. materials }\end{array}$ & 30 & $\begin{array}{l}50.77 \\
56.20\end{array}$ & $\begin{array}{l}4.79 \\
2.85\end{array}$ & -5.00 & 0.000 & $\begin{array}{l}\text { Sig. Statistical difference } \\
\text { in sexual function }\end{array}$ \\
\hline
\end{tabular}


Table 2. The $\mathrm{T}$ test for the two independent groups to know the differences in the sexual function and the psychological state among women with $\mathrm{BrCa}$ between the experimental program group and the educational materials group.

\begin{tabular}{cccccccc}
\hline Variables & Groups & No. & Mean & $\begin{array}{c}\text { Standard } \\
\text { Deviation }\end{array}$ & T. Value & $\begin{array}{c}\text { P. } \\
\text { Value }\end{array}$ & Conclusion \\
\hline \multirow{2}{*}{ WSFQ } & Intervention & 29 & 50.76 & 6.29 & \multirow{2}{*}{4.83} & 0.001 & $\begin{array}{c}\text { Sig. Differences in favor of the } \\
\text { educational materials group } \\
\end{array}$ \\
Education & 30 & 56.20 & 4.89 & & & Sig. Differences in favor of the \\
educational materials group
\end{tabular}

Table 3. T test for the two independent groups to acknowledge the differences in sexual and psychological functioning among BrCa women between the educational materials and control groups.

\begin{tabular}{cccccccc}
\hline Variables & Groups & No. & Mean & $\begin{array}{c}\text { Standard } \\
\text { Deviation }\end{array}$ & T. Value & $\begin{array}{c}\text { P. } \\
\text { Value }\end{array}$ & Conclusion \\
\hline \multirow{2}{*}{ WSFQ } & Education & 30 & 56.20 & 4.89 & \multirow{2}{*}{1.79} & 0.078 & $\begin{array}{c}\text { No significant differences were found } \\
\text { between the two groups }\end{array}$ \\
& Control & 30 & 53.50 & 6.63 & & & Significant differences were found \\
HADs & Education & 30 & 5.87 & 2.84 & \multirow{2}{*}{5.08} & 0.001 & between the two groups \\
& Control & 30 & 11.10 & 4.86 & &
\end{tabular}

Table 4. Demographic characteristics of all participants; Educational (Edu.) G., Intervention (Inter.) G. and control (C.) G.

\begin{tabular}{|c|c|c|c|}
\hline Variable & No. Of Participants \& \% & Variable & No. Of Participants \& \% \\
\hline \multicolumn{4}{|l|}{ Age } \\
\hline Less than 30 & $6(7 \%)$ & Diagnosis time & \\
\hline 31- 40 & $19(21 \%)$ & Less than $6 \mathrm{~m}$ & $16(18 \%)$ \\
\hline $41-50$ & $43(48 \%)$ & $7-11 m$ & $36(40 \%)$ \\
\hline 50 \& above & $21(24 \%)$ & $12 \mathrm{~m}$ and more & $37(42 \%)$ \\
\hline Level of edu. & & Stage of disease & \\
\hline Illiterate & $8(9 \%)$ & 2 & 25 (29\%) \\
\hline Primary & $28(31 \%)$ & 3 & $25(29 \%)$ \\
\hline High School & 31 (35\%) & 4 & $22(23 \%)$ \\
\hline University and above & $22(25 \%)$ & & $17(19 \%)$ \\
\hline $\begin{array}{l}\text { Occupation } \\
\text { Unemployed } \\
\text { Employed }\end{array}$ & $\begin{array}{l}63(71 \%) \\
26(29 \%)\end{array}$ & $\begin{array}{c}\text { Type of treatment } \\
\text { Surgery } \\
\text { Chemo } \\
\text { Radio } \\
\text { Tamox. }\end{array}$ & $\begin{array}{l}78(88 \%) \\
85(96 \%) \\
40(45 \%) \\
60(67 \%)\end{array}$ \\
\hline $\begin{array}{c}\text { Region of Living } \\
\text { East } \\
\text { Middle } \\
\text { North } \\
\text { West }\end{array}$ & $\begin{array}{c}8(9 \%) \\
49(55 \%) \\
10(11 \%) \\
22(25 \%)\end{array}$ & & \\
\hline
\end{tabular}

on an outpatient basis, leaving patients to manage side effect at home [11].

Women assigned to the psychosexual intervention program did not have significant higher posttest scores on neither HADS nor WSFQ scales than women assigned to educational materials group (Table 2). On the contrary women assigned to educational materials have significant low scores in post test HADS and higher scores in regard to post test WSFQ than women assigned to the intervention program. It is useful to be reminded that such a result might assume lack of adequate evidence of the efficacy of the program which is not the case. But as in one study found an educational material such as giving patients DVD was considered highly acceptable by patients and was found to increase self-efficacy and reduce supportive care needs. Hence, it is appropriate to give patients before face-to-face chemotherapy education [11].

The main objective of constructing this three arms experimental design study is to introduce the second experimental group which characterized by having the educational materials only. Benefit of educational materials had been mentioned in the literature and many studies [11] [9] indicates that it can substitute and function as much as the provision of the whole intervention program because introducing the program regularly to patients is not practical especially given the circumstances of RICK, the patients inadequate financial resources to come 
from their remote areas where they live to the hospital, their limited view to the psychological support and sometimes the strong net work social support system found in Sudanese culture.

Patients, who get information about the stressful event they experience, may feel more in control and less depressed, and in response, adjust better than those not receiving information. One study adds to these findings by indicating that information benefit patients at high risk for psychological distress, that is, patients low in control and high in illness uncertainty [9]. That's confirmed by the significant differences which were found regarding HADS scores between the educational materials group and the control (Table 3). These differences were mainly due to the improvement in scores for the educational materials group unlike the control group who stayed the same and did not show any progress in HADS post test analysis (Table 3 ).

In addition to that one should bear in mind that there was difference in the improvement of score that has been found among the educational materials group pre and post tests analysis while when compared to the control group a slight drop in scores was found in post tests in the latter group. Generally, information is typically perceived as important, even by those who adopt a passive role in relation to treatment decision-making [2].

Therefore focusing on educational materials in sort of; booklets, pamphlets, brochures and so on can improve the knowledge among patients high in illness uncertainty. For instance, reading that most patients adjust well after chemotherapy treatment or that decrease in sexual desire may still be present after therapy but eventually will come back to normal, may have given these patients insight into the effects of chemotherapy. Most of our patient's women exaggerate and bothered by losing their hair (as observed in the sessions) hence knowing in advance or providing them with educational materials that will remind them about hair will grow again, will decrease any future disturbances in psychological health or in their body image.

Finally, information giving goes beyond the period of treatment to the period after treatment as many patients continue to have problems and need to be preparing for handling them. But because patients cease to visit the hospital regularly until their first follow-up, it is in general difficult for health-care providers to detect these problems and to intervene. In addition, patients may not always find their way to the health-care team during this post-treatment phase [9].

\section{Conclusion}

The study concluded that, as patients cease to visit the hospital regularly until their first follow-up, it is in generally difficult for health-care providers to detect problems and hence to intervene. Information giving in form of educational materials goes beyond the period of treatment as many patients continue to have problems and need to be preparing for handling them.

\section{References}

[1] Baum, A. and Andersen, B. (2002) Psychosocial Intervention for Cancer. American Psychological Association, Washington, DC.

[2] Gray, R.E., Fitch, M., Greenberg, M., Hampson, A., Doherty, M. and Labrecque, M. (1998) The Information Needs of Well, Longer-Term Survivors of Breast Cancer. Patient Education and Counseling, 33, 245-255. http://dx.doi.org/10.1016/S0738-3991(98)00024-X

[3] Davey H.M, Barratt A.L, Butow, P.N. and Houssami, N. (2008) The Impact of Different Criteria for Selecting Information to Be Provided to Women Undergoing Diagnostic Breast Tests. Patient Education and Counseling, 71, 86-94. http://dx.doi.org/10.1016/j.pec.2007.12.001

[4] Takahashi, M., Ohno, S., Inoue, H., Kataoka, A., Yamaguchi, H., Uchida, Y., Oshima, A., Abiru, K., Ono, K., Noguchi, R. and Kai, I. (2007) Impact of Breast Cancer Diagnosis and Treatment on Women's Sexuality: A Survey of Japanese Patients. Psycho-Oncology, 17, 901-907. http://dx.doi.org/10.1002/pon.1297

[5] Sollner, W., Maislinger, S., Konig, A., Devries, A. and Lukas P. (2004) Providing Psychosocial Support for Breast Cancer Patients Based on Screening for Distress within a Consultation-Liaison Service. Psycho-Oncology, 13, 893-897. http://dx.doi.org/10.1002/pon.867

[6] Carlson, L.E. and Bultz, B. (2004) Efficacy and Medical Cost Offset of Psychosocial Interventions in Cancer Care: Making the Case for Economic Analysis. Psycho-Oncology, 13, 837-849. http://dx.doi.org/10.1002/pon.832

[7] Hewitt, M.E., Herdman, R. and Holland, J.C. (2004) Meeting Psychosocial Needs of Women with Breast Cancer. National Cancer Policy.

[8] Katz, M.R., Irish, J.C. and Devins, G.M. (2004) Development and Pilot Testing of a Psycho-Educational Intervention 
for Oral Cancer Patients. Psycho-Oncology, 13, 642-653. http://dx.doi.org/10.1002/pon.767

[9] Steigelis, H.E., Hagedoorn, M., Sandrman, R., Bennenbroek, F.T.C., Buunk, B.P., Van Den Bergh, A.C.M., Botke, G. and Ranchor, A.V. (2004) The Impact of an Informational Self-Management Intervention on the Association between Control and Illness Uncertainty before and Psychological Distress after Radiotherapy. Psycho-Oncology, 13, 248-259. http://dx.doi.org/10.1002/pon.738

[10] Fallowfield, L. (1997) Offering Choice of Surgical Treatment to Women with Breast Cancer. Patient Education and Counseling, 30, 209-214. http://dx.doi.org/10.1016/S0738-3991(96)00947-0

[11] Schofield, P., Jefford, M., Carey, M., Thomson, K., Evans, M., Baravelli, C. and Aranda, S. (2008) Preparing Patients for Threatening Medical Treatments: Effect of a Chemotherapy Educational DVD on Anxiety, Unmet Needs and SelfEfficacy. Supportive Care in Cancer, 16, 37-45. http://dx.doi.org/10.1007/s00520-007-0273-4 